\title{
SOME THEOREMS AND PROCEDURES IN SHALLOW-WATER OCEANOGRAPHY APPLIED TO THE CELTIC SEA
}

\author{
By L. H. N. COOPER \\ The Plymouth Laboratory
}

\section{(Text-figs I-5)}

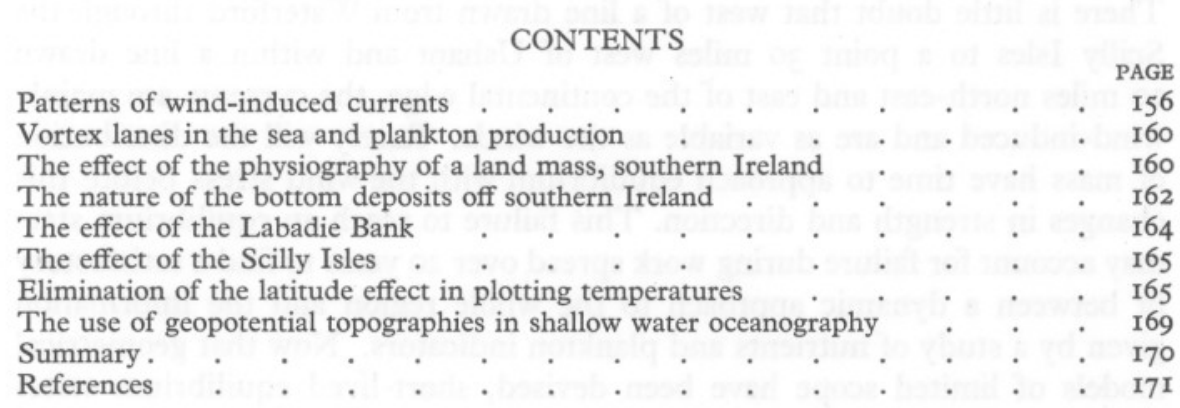

Twenty years ago the Plymouth Laboratory investigated the spawning of mackerel and pilchard in the Celtic Sea. The physical background for their work, which the late Dr G. A. Steven and Mr P. G. Corbin sought, could not be provided since waters with similar temperatures and salinities evidently had very different physical and biological histories.

Thus any study of the physical and chemical oceanography of the Celtic Sea, as of other waters around Britain, is an industrial rather than a fundamental research. Answers are needed for practical ends so that an imperfect answer today may be as useful as a thorough understanding tomorrow. In such circumstances oceanographers fall back on intuitions, which they cannot defend, to amplify inadequate observation. Since my own views about the Celtic Sea were so largely intuitive they have never been published. In 1948, an attempt at rationalization was made, much in the form to be presented here. Some of the theorems were used as working hypotheses when the I950 programme was designed and proved compatible with the observations (Cooper, 1960, and in preparation), others remained shelved awaiting opportunity for tests which have never come. Now that 9 more years have passed, these theorems may help to build a bridge with findings in the same area by the Lowestoft Fisheries Laboratory. No more is claimed than that no theorem is in conflict with observations some of which will be published in a paper now in preparation. 
In order to understand the water circulation better, it is essential to appreciate the pattern of winds over the area and what they are likely to do to the sea, to understand the effects of the physiography of the sea bed and of the neighbouring land on currents, and to eliminate the effect of latitude on temperature. These problems have been examined and some conclusions drawn. Their importance is that if they are indeed true, then they may always be true and applicable on occasions when only few observational records are available.

\section{PATTERNS OF WIND-INDUCED CURRENTS}

There is little doubt that west of a line drawn from Waterford through the Scilly Isles to a point 30 miles west of Ushant and within a line drawn 20 miles north-east and east of the continental edge, the currents are mainly wind-induced and are as variable as the winds. Rarely will the distribution of mass have time to approach equilibrium with the wind stress before this changes in strength and direction. This failure to reach an equilibrium state may account for failure during work spread over 20 years to find a satisfactory fit between a dynamic approach to the whole region and the information given by a study of nutrients and plankton indicators. Now that geometrical models of limited scope have been devised, short-lived equilibrium states may be recognized and studied with more hope of success.

Any steady wind over deep water should produce, in accordance with Ekman's (1905) theory, a surface current $45^{\circ}$ to the right of the wind direction. In shallow water unrestricted by any land mass this angle will be smaller the less the depth of water and the stronger the wind. In summer the thermocline acts as a false bottom so that above a thermocline or above any discontinuity layer the current will run more nearly in the direction of the wind. In Fig. I the system of currents that should result in the Celtic Sea and English Channel from winds from six directions are presented for winter conditions.

Over a fairly small sea area such as the Celtic Sea, it should be possible to compute the torque exerted on the surface of the Celtic Sea from wind records at coastal observatories. For the 5 weeks preceding the cruise of April I950, the pattern of winds at three well-placed exposed meteorological stations has been examined, viz. Scilly, St Ann's Head in Pembrokeshire, and Valentia in County Kerry. The period has been broken down into five parts each with a well-defined wind pattern (Table I) and then summed up for the whole period. Vector addition has been used.

The direction of the mean wind measured over the whole 5 weeks at St Ann's Head was over $30^{\circ}$ greater than at Scilly-251 $1^{\circ}$ as compared with $218^{\circ}$. Moreover, a similar difference showed up on each of the five shorter periods with winds from east through south to west-north-west. However, the difference in wind direction may be due to differences of latitude, or 


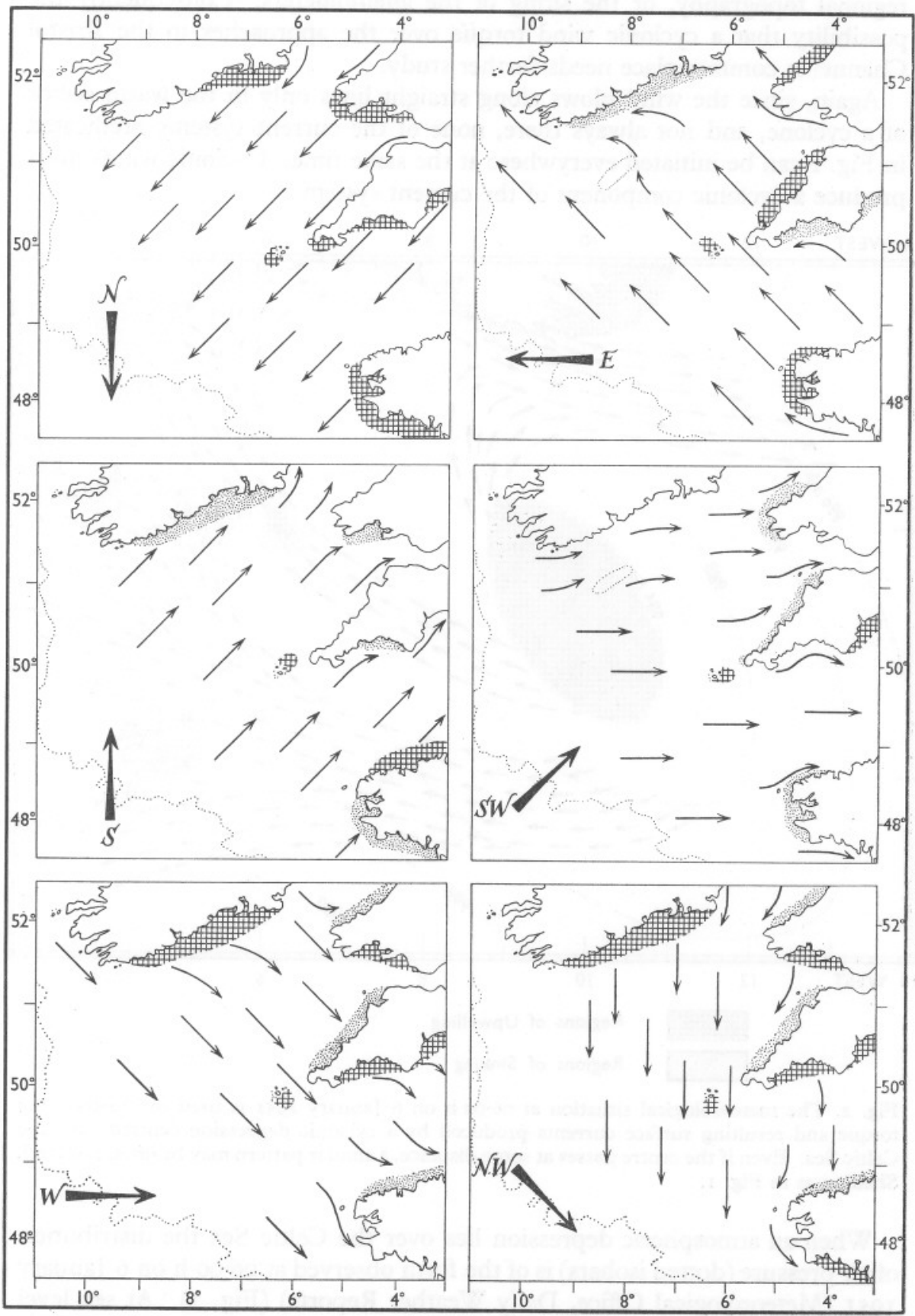

Fig. I. Hypothetical system of surface currents induced in the Celtic Sea by winds in winter. The direction of the wind is shown by the heavy arrow in the bottom left-hand corner. Areas where upwelling should be favoured are cross-hatched. Areas where water must escape by sinking or by strong coastal flows are stippled. 
regional topography, or the siting of the anemometers. Consequently the possibility that a cyclonic wind torque over the approaches to the Bristol Channel is commonplace needs further study.

Again, since the wind blows along straight lines only in the warm sector of a cyclone, and not always there, none of the current systems predicated in Fig. I can be initiated everywhere at the same time. Cyclonic winds must produce a cyclonic component of the current system.

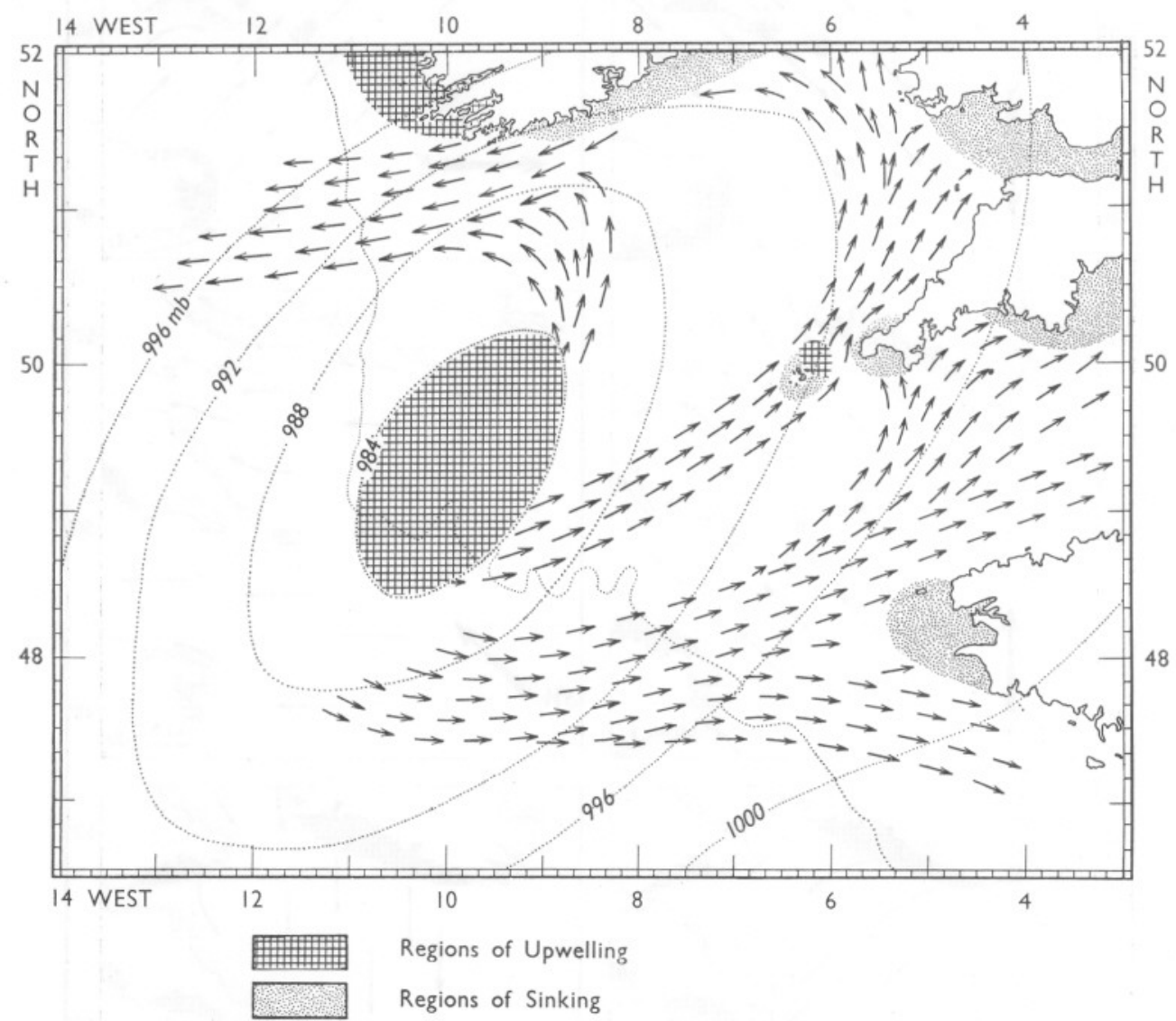

Fig. 2. The meteorological situation at $06.00 \mathrm{~h}$ on 6 January $\mathrm{I} 95 \mathrm{I}$ is used to illustrate the torque and resulting surface currents produced by a cyclonic depression centred over the Celtic Sea. Even if the centre passes at some distance, a similar pattern may be often resolved. Shading as in Fig. I.

When an atmospheric depression lies over the Celtic Sea the distribution of air pressure (dotted isobars) is of the form observed at $06.00 \mathrm{~h}$ on 6 January 195I (Meteorological Office, Daily Weather Reports) (Fig. 2). At sea level the resulting cyclonic wind was blowing across the isobars inwards towards 
the centre. Since the surface water current at every point would be initiated to the right of the surface wind direction, the surface currents will diverge a few degrees to the right of the isobars. Under the centre of the depression, a vortex will tend to form, accompanied by upwelling and diverging surface currents. In compensation, bottom water must converge on the vortex. Its course will be much influenced by the bottom topography.

The land constrains the current system absolutely so that the atmospheric pressure system on the morning of 6 January I95I would have initiated a current system such as that in Fig. 2.

Such an atmospheric pressure distribution ought therefore to produce a torque on the sea surface, and it is this over-all torque and not the wind direction and strength at any one position which may produce the cyclonic circulation of the Celtic Sea.

TABLE 1. INTEGRATED MEAN WIND DIRECTIONS AT THREE METEOROLOGICAL STATIONS BORDERING THE CELTIC SEA

Period 1950

I4 March, 00.00 h-24 March, 06.00 h 24 March, 12.00 h-29 March, 12.00 h

29 March, I8.00 h-5 April, $06.00 \mathrm{~h}$

5 April, $12.00 \mathrm{~h}-7$ April, $24.00 \mathrm{~h}$

8 April, 06.00 h-17 April, 24.00 h

I4 March, 00.00 h-I7 April, 24.00 h

\begin{tabular}{|c|c|c|c|c|}
\hline \multirow[b]{2}{*}{$\begin{array}{c}\text { No. of } \\
\text { observations }\end{array}$} & \multicolumn{3}{|c|}{ Mean wind direction } & \multirow{2}{*}{$\begin{array}{l}\text { Difference: } \\
\text { St Ann's } \\
\text { Head-Scilly }\end{array}$} \\
\hline & $\begin{array}{l}\text { St Ann's } \\
\text { Head }\end{array}$ & Scilly & Valentia & \\
\hline 42 & $233 \frac{1}{2}^{\circ}$ & $202^{\circ}$ & $179^{\circ}$ & $+31^{\frac{1}{2}}{ }^{\circ}$ \\
\hline $2 \mathrm{I}$ & II $8^{\circ}$ & $66^{\circ}$ & $134 \frac{1}{2}^{\circ}$ & $+52^{\circ}$ \\
\hline 27 & $306 \frac{1}{2}^{\circ}$ & $28 \mathrm{I}^{\circ}$ & $300^{\circ}$ & $+25 \frac{1}{2}^{\circ}$ \\
\hline II & $205^{\frac{1}{2}} \circ$ & $164^{\circ}$ & $193^{\circ}$ & $+4 \mathrm{I}^{\frac{1}{2}}{ }^{\circ}$ \\
\hline 40 & $292^{\circ}$ & $278^{\circ}$ & $283^{\circ}$ & $+14^{\circ}$ \\
\hline I4I & $25 \mathrm{I}^{\circ}$ & $218^{\circ}$ & $226^{\circ}$ & $+33^{\circ}$ \\
\hline
\end{tabular}

The centre of a cyclonic depression passes over the Celtic Sea not very often and when it does it stays there not very long. Occasions when a simple circulation such as that in Fig. 2 may be initiated may be rare. Nevertheless, when a depression passes over or near the British Isles, and that is often, a cyclonic torque may be resolved from the depression and will be operative over the Celtic Sea as a whole and it is this torque rather than a south-westerly wind off Ushant or a north-easterly one off southern Ireland which produces the observed circulation. It may therefore often prove necessary to combine two or more of the charts in Fig. I for different parts of the area to evaluate a real occasion.

In summer when the thermocline forms, the arrows in Fig. I all require to be rotated in an anticlockwise direction. A study of the currents around Ushant (Cooper, I960) has shown that just such a change in current direction occurred there after the thermocline had formed in the summer of 1950 . If the conclusion may be generalized, as probably it may, it could be of importance for studies on the seasonal drift of fish eggs anywhere. 


\section{VORTEX LANES IN THE SEA AND PLANKTON PRODUCTION}

Beneath the centre of a depression a vortex will be created in the sea to a considerable depth. Under extreme conditions the water in this vortex may be carried upwards into the air as a waterspout. In winter the vertical column approaches homogeneity so that the vortex can do little by further mixing the water column but, even then, it may have an effect by disturbing bottom deposits. When the water is stratified, as often in summer, the passage of a deep depression in the atmosphere may produce, by upwelling in the sea beneath it, a 'vortex lane' of surface enrichment. Along this vortex a summer outburst of phytoplankton may possibly ensue.

The upwelling vortex in shallow seas is likely to create considerable disturbance of light bottom deposits and occluded dissolved products of regeneration and to suck these towards the surface. A vortex lane should become characterized by a high content not only of total phosphorus, silicate and bacteria but also of chemical substances which affect the growth of plants and animals. This phenomenon should be especially marked over mud bottoms. Phytoplankton outbursts in a vortex lane are therefore likely to consist of a few species which find conditions especially favourable. Similarly animals which spawn into a vortex lane will find exceptional conditions (cf. Wilson, I95I; Cooper, I95I) which may be favourable to some. The zooplankton which subsequently develops may possibly include characteristic indicator species.

\section{THE EFFECT OF THE PHYSIOGRAPHY OF A LAND MASS, SOUTHERN IRELAND}

The currents in the northern Celtic Sea may be much influenced by the physiography of southern Ireland. Between Dungarvan Harbour and Cape Clear the coast runs E.N.E.-S.S.W. Winds from south-south-west will tend to initiate currents along the coastline (cf. Fig. I). Winds between south-west and north-west will tend to cause a similar coastal current but with an off-shore set at the surface.

The main drainage of south-western Ireland runs in deeply cut valleys from west to east or vice versa (Fig. 3). Although several of the original west-east rivers have been captured by others which have cut south across the ridges, the original valleys will channel surface winds from between northwest and south-west, so that they reach the coast in the neighbourhood of Waterford, Dungarvan and Youghal harbours more nearly from due west. There they should tend to produce a series of parallel off-shore currents setting between east-south-east and south-east. Waterford Harbour not only receives the Suir from the west, connected by a low watershed to the valley of the Shannon estuary, but the Barrow which has cut for itself a deep valley running for 50 miles practically due south along the meridian $6^{\circ} 57^{\prime} \mathrm{W}$. This 
will similarly channel northerly winds which, whilst they blow, should initiate a current setting south-south-west or south-west off Waterford Harbour.

These are upwelling situations likely, when the wind is favourable, to initiate productive centres, particularly off Waterford at about $5 \mathrm{I}^{\circ} 40^{\prime} \mathrm{N} ., 7^{\circ} \mathrm{W}$. This effect of physiography has been used by Cromwell (1956) to explain the productivity of the Gulf of Tehuantepec on the Pacific coast of southern Mexico. There strong or gale force northerly winds blow through the low and narrow Tehuantepec Pass on to the Gulf to produce an upwelling situation.

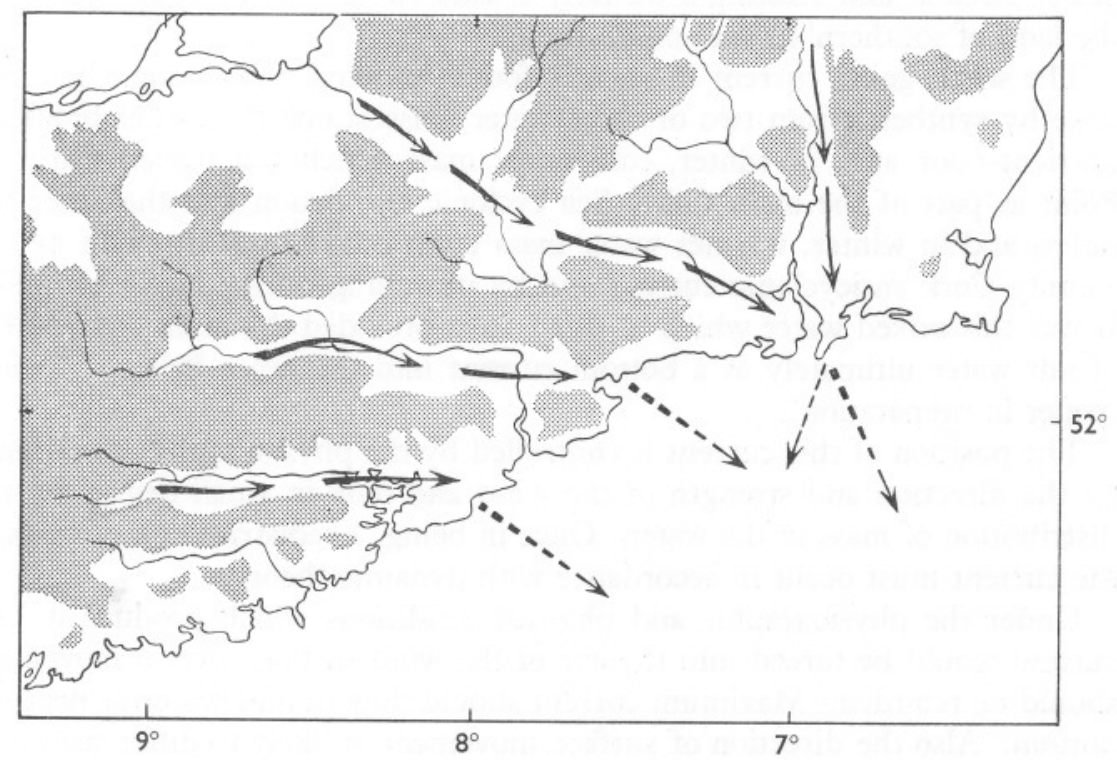

Fig. 3. To illustrate the effect of the prevailing westerly and south-westerly winds combined with the physiography of southern Ireland on currents and upwelling in the northern Celtic Sea. The effect of northerly winds channeled by the Barrow valley is also shown.

The prevailing winds of southern Ireland, which often blow with gale force, should therefore tend to create coastal currents towards the east often trending away from the coast.

To oppose this current system, the Coriolis force operating on the main cyclonic circulation system of the Celtic Sea and favoured by the light coastal belt of water of low salinity will tend to create a coastal current setting west or west-south-west along the length of southern Ireland. Moreover, the two opposed tendencies are produced by much the same winds and may therefore be in frequent conflict. The conflict can only be relieved by a current setting south away from the coast and this seems most often to occur in $7^{\circ} \mathrm{W}$., the longitude of Waterford Harbour. This may be pictured as a large-scale rip current (Shepard, 1948). The analogy should not be pressed too far and the 
term 'rip' should not be transferred. Such a current shows the site of a surface divergence. A cyclonic wind system may therefore produce an anticyclonic current south of County Cork which may force the main cyclonic circulation into a narrow ellipsoidal figure lying east of $8^{\circ} \mathrm{W}$. long.

The main cyclonic eddy is much the greater and contains much more water and momentum than the County Cork anticyclonic current. Consequently as soon as the westerly or south-westerly winds die down the main cyclonic current should become dominant, spreading westwards, becoming more nearly circular and creating a westerly coastal current of the usual type with the land of southern Ireland on its right.

The south-going current frequently found in about $7^{\circ} \mathrm{W}$. long. thus may arise by synthesis from two or three water masses, one the rather brackish, nutrient-poor and, in winter, cold water mass which has passed Carnsore Point as part of the main Celtic Sea cyclonic circulation and the other the salter, and in winter, warmer water mass contributed from the west by the County Cork anticyclonic current and by upwelling during northerly gales. It was this mixed water which in April 1950 provided the main recruitment of salt water ultimately as a bottom current into the inner Bristol Channel (paper in preparation).

The position of this current is controlled by the physiography of the land, by the direction and strength of the wind and only in small degree by the distribution of mass in the water. Once in being, a redistribution of mass in the current must occur in accordance with dynamic theory.

Under the physiographic and physical conditions which produce it, this current would be forced into the eye of the wind so that surface movement should be retarded. Maximum current should flow in mid-water or near the bottom. Also the direction of surface movement is likely to differ markedly from that near the bottom. Surface movement should trend south-west, midwater south-east, and bottom movement east towards the Bristol Channel. The Ekman spiral would seem not to apply to such a current forced to flow against the direction of the wind. Under such conditions no help in sketching its course is to be expected from charts of dynamic height anomalies (geopotential topographies).

\section{THE NATURE OF THE BOTTOM DEPOSITS OFF SOUTHERN IRELAND}

The topography of the bed of the Celtic Sea has been contoured and described by Robinson (1952). Matthews (1914) pointed to the importance of the weak tidal streaming and small scour in favouring deposition of mud between about $5 \mathrm{I}^{\circ} \mathrm{N}$., $6^{\circ} \mathrm{W}$. and the coast of County Waterford.

Much information as to the nature of the bed of the Celtic Sea is given on old charts published privately and by the Hydrographic Office. Off the south coast of Ireland in depths of about $35-40 \mathrm{fm}$. there are many references to 
'mud' and 'ooze'. Along the south coast of Cornwall, which in its physiography and exposure to wind has much in common with southern Ireland, no such deposits of mud and ooze were reported nor, indeed, are found by our research ships.

Again, off southern Ireland, there are many records of 'muddy stones', 'muddy gravel', or 'mud' with 'stones' nearby at a similar depth. The picture one has is of an area of what on land would be called boulder clay, deposited during the southernmost extension of glaciation in Ireland. If so the stones have lain there uncovered for at least 10,000 years. Much of the mud, therefore, can be no more than a veneer. If the area was one of strong unidirectional residual currents, as the south coast of Cornwall seems to be, detritus would be swept away to be deposited somewhere else. It would not collect even as a veneer.

If this interpretation as an area of boulder clay overlain by a veneer of mud is correct, we have an equilibrium system: (a) the area is one of weak currents which enable mud to be deposited or of horizontal or vertical eddies which tend to concentrate detritus to settle on the bottom beneath, but $(b)$ the area is also one where the muddy deposits are creamed off probably intermittently as the result of storm action to be redeposited further south or west. Coring work in this region is badly needed.

A solution may be approached in two ways. Detritus, even organic detritus, is heavier than water, and so tends to settle on the bottom. Our prevailing winds tend to produce an upwelling situation along the south coast of Ireland. Detritus caught up in such a situation will tend to undergo a cyclic movement. Material inshore near the bottom may rise with the upwelling water to be carried seaward in the surface offset. From this it would settle into the deeper water some of which will be drawn back towards the site of upwelling.

Although by itself this mechanism would be insufficient to build up a muddy deposit, it would seem to be a necessary component of one that might. Its biochemical implications need also to be considered. If the detritus should consist of a pure clay mineral it would have no nutrient value and would reduce the amount of light available for photosynthesis. Its effect would be adverse. The clay might carry adsorbed materials which have value to plants. The important part of the detritus, sometimes called seston, would be organic material resulting from death and defaecation and capable of yielding breakdown products essential for the subsequent success of plants and animals in the water. Such organic detritus, only slightly heavier than water, cycling in this way, is particularly likely to provide an explanation of the richness established along the south coast of Ireland by the Lowestoft and Plymouth research vessels in $1958-59$.

This mechanism would also favour the concentration of zooplankton which undergo vertical migration from surface to bottom. It would, however, do them no good unless they found food to live on. 
This argument would apply equally to much of the south coast of Cornwall, particularly off the Helford River. I know of no evidence for it there. There is, however, a second line of argument which complements the first.

In general, in the northern hemisphere, the outflow of rivers tends to build up a zone of brackish coastal water which, except sometimes at the time of minimum temperature, creates a band of light water which flows with the coast on its right. Along the south coast of Ireland, this current would flow from east to west. However, the direction of the prevailing winds combined with the physiography of the area may, as we have seen, require a current along this coast in the opposite direction, west to east. Evidence for its existence in April 1950 will be produced in a later paper. When these tendencies cancel each other to produce no residual current in a region where tidal currents are weak, the load of detritus may be dropped.

At the Daunt light vessel off Cork Harbour, the table of the tidal stream given on Admiralty chart no. 2049 bears this annotation: 'Wind has so much effect on the direction and rate of the tidal streams at this position that the above table can only be looked upon as approximate and the stream may sometimes be found running even in the contrary direction to that given for any hour in the table'. South of the Daunt light vessel Imray's old chart shows many entries for mud.

By combining the two arguments the difference between the bottom deposits off the south coasts of Ireland and of Cornwall, which otherwise have so much in common, may be explained.

A study of these muddy bottoms may, therefore, for several reasons have a proper place in fisheries research.

\section{THE EFFECT OF THE LABADIE BANK}

The Labadie Bank, 20 miles long but only 3 miles wide, extends in a direction south-west by west and lies about 60 miles off the Irish Coast. It rises $40 \mathrm{~m}$ from the sea bed in $110 \mathrm{~m}$ and is connected by deeper spurs with the Cockburn and Great Sole Banks lying more than 60 miles to the south-west. This system of banks may exert some control over currents in their neighbourhood and tend to make them conform to a north-easterly-south-westerly pattern.

The Bank lies athwart the general south-easterly and southerly trend of the County Cork anticyclonic current. Both the Coriolis force and the pressure of the main Celtic Sea cyclonic circulation tend to turn this current to the right or south-west in line with the constraint imposed by the Bank. On many occasions the Labadie Bank may provide the southern limit of the County Cork anticyclonic system.

The degree of permanence of this anticyclonic system has not yet been assessed but it is likely that on occasion it may last long enough to become markedly enriched from the mud deposits of the Labadie area (Cooper, 195I) 
and off the south coast of Ireland, not only with inorganic nutrients but with growth-affecting substances as well. Then distinctive chemical composition may lead in time to the development of characteristic biological indicator species.

THE EFFECT OF THE SCILLY ISLES

The Scilly Isles comprise a few small inhabited islands and a large number of rocks rising from an elevation of the sea floor about II miles long and 5 miles wide. The surrounding sea floor lies at $70-80 \mathrm{~m}$, whereas the depth of water within the islands ranges from $\mathrm{I} 5$ to $45 \mathrm{~m}$. There can be but little land drainage to affect the density of the water.

When air temperature is below sea temperature, as frequently in autumn and winter, the water within the island group will be cooled further and become heavier than in the adjacent sea (Cooper \& Vaux, I949). It will therefore sink and flow out by the deepest channels, North Channel and Broad Sound on the western side of the Isles. To replace this loss, surface water will be drawn in through the many surface channels so that a cyclonic current will be created round the Isles (Sandström, I9I8, fig. 4I $a$ ).

When air temperature is above sea temperature or much solar radiation is being received, the sea surface will warm up everywhere but, due to the rugged bottom topography of the Isles, vertical mixing there would be expected to extend deeper than in the adjacent open sea. Although the surface water may become slightly cooler, the vertical water column as a whole should become lighter than outside. A rising centre has come into being so that there will be a tendency for water to be drawn in through the two deepest channels and ejected at some depth between the surface and the depth of the thermocline outside.

These conditions are more complicated than those associated with cooling but the net effect would seem to be to create a divergent anticyclonic current round the Isles at or just above the level of the thermocline.

It is not considered that these trends will ever be dominant but that they will modify currents near the Isles due to other causes. Carruthers, Lawford \& Veley (I95I) have found that at the Seven Stones Light Vessel, 9 miles E.N.E. of the islands, the current sets on the average towards $110^{\circ}$ true. On this view during cold weather this current should set more nearly east, whereas in warm sunny weather it should set more nearly south. When such fluctuations are actually observed they may need to be interpreted not in terms of a major change in the current system of the Celtic Sea, but as no more than a local effect due to the presence of the Scilly Isles.

\section{ELIMINATION OF THE LATITUDE EFFECT IN PLOTTING TEMPERATURES}

In these investigations charts and sections of temperature did not at first prove helpful. It is not easy to deduce currents with a meridional component from 
plots of temperature because as a current moves southward it is warmed by insolation to a greater extent than it loses heat by radiation and evaporation. Such a current is also continuously warming up by lateral mixing with warm water through which it flows.

When, as in our April 1950 cruise, the lay-out of the sections is latitudinal, it is worth while to eliminate the effect of latitude. Calculating along the fiftieth parallel, as shown in Table 2, the effect of uneven spacing of the stations is eliminated. Between Lands End and a point north of Scilly, stations were 7 miles apart, whereas to the westward the interval was 30 miles. Proper weight is given to the length of the section which each station must represent.

TABLE 2. MEAN TEMPERATURES ALONG $50^{\circ} \mathrm{N}$. (FIRST APPROXIMATION) $10 \cdot 17^{\circ}$

\begin{tabular}{|c|c|c|c|c|c|c|c|c|}
\hline Station & $\begin{array}{l}\text { Lat. } \\
\left({ }^{\circ} \mathrm{N} .\right)\end{array}$ & $\begin{array}{l}\text { Long. } \\
\left({ }^{\circ} \mathrm{W} .\right)\end{array}$ & $\begin{array}{l}\text { Limits } \\
\text { represented } \\
\text { by station } \\
\left(\text { long. }{ }^{\circ}\right)\end{array}$ & $\begin{array}{c}\text { Minutes } \\
\text { of } \\
\text { long. } \\
(\Delta \lambda)\end{array}$ & $\begin{array}{l}\text { Observed } \\
\text { temp. }{ }^{\circ} \mathrm{C}\end{array}$ & $\begin{array}{c}\theta= \\
T-10^{\circ}\end{array}$ & $\theta \Delta \lambda$ & $\begin{array}{l}\text { Temp. } \\
\text { correct to } \\
50^{\circ} 0^{\prime} \mathrm{N}\end{array}$ \\
\hline 20 & $49^{\circ} 57^{\prime}$ & $9^{\circ} 06^{\prime}$ & $\begin{array}{l}9^{\circ} 15^{\prime} \\
8^{\circ} 55^{\prime}\end{array}$ & $20^{\prime}$ & 9.99 & -0.01 & -0.20 & $9 \cdot 97$ \\
\hline 21 & $49^{\circ} 56^{\prime}$ & $8^{\circ} 45^{\prime}$ & $8^{\circ} 38^{\prime}$ & $17^{\prime}$ & $10 \cdot 15$ & 0.15 & +2.55 & $10 \cdot 12$ \\
\hline 22 & $49^{\circ} 58^{\prime}$ & $8^{\circ} 3 I^{\prime}$ & $8^{\circ} 13^{\prime}$ & $25^{\prime}$ & $10 \cdot 17$ & 0.17 & $+4 \cdot 25$ & $10 \cdot 16$ \\
\hline 23 & $50^{\circ} \circ 3^{\prime}$ & $7^{\circ} 55^{\prime}$ & $7^{\circ} 4^{\frac{1}{2}}{ }^{\prime}$ & $30 \frac{1}{2}^{\prime}$ & $10 \cdot 33$ & 0.33 & +10.07 & 10.35 \\
\hline 24 & $50^{\circ} \circ 0^{\prime}$ & $7^{\circ} 30^{\prime}$ & $7^{\circ} 13^{\prime}$ & $29 \frac{1}{2}^{\prime}$ & $10 \cdot 20$ & 0.20 & +5.90 & 10.20 \\
\hline 25 & $49^{\circ} 58^{\prime}$ & $6^{\circ} 56^{\prime}$ & $6^{\circ} 45^{\prime}$ & $28^{\prime}$ & $10 \cdot 16$ & 0.16 & $+4 \cdot 48$ & $10 \cdot 15$ \\
\hline 26 & $50^{\circ} \circ 4^{\prime}$ & $6^{\circ} 34^{\prime}$ & $6^{\circ} 27^{\frac{1}{2}}$ & $17 \frac{1}{2}^{\prime}$ & $10 \cdot 20$ & 0.20 & +3.50 & 10.23 \\
\hline 27 & $50^{\circ} 04^{\prime}$ & $6^{\circ} 21^{\prime}$ & $6^{\circ} 18^{\prime}$ & $9^{1^{\prime}}$ & $10 \cdot 10$ & 0.10 & +0.95 & 10.13 \\
\hline 28 & $50^{\circ} 04^{\prime}$ & $6^{\circ} 15^{\prime}$ & $6^{\circ} \mathrm{II}^{\prime}$ & $7^{\prime}$ & 10.08 & 0.08 & +0.56 & IO.II \\
\hline 29 & $50^{\circ} 04^{\prime}$ & $6^{\circ} 07^{\prime}$ & $6^{\circ} 03 \frac{1}{2}^{\prime}$ & $7 \frac{1^{\prime}}{}$ & $10 \cdot 17$ & 0.17 & $+I \cdot 28$ & $10 \cdot 20$ \\
\hline 30 & $50^{\circ} 04^{\prime}$ & $600^{\prime}$ & $5^{\circ} 56 \frac{1}{2}^{\prime}$ & $7^{\prime}$ & 10.08 & 0.08 & +0.56 & IO.II \\
\hline $3 I$ & $50^{\circ} 04^{\prime}$ & $5^{\circ} 53^{\prime}$ & $5^{\circ} 49^{\prime}$ & $7 \frac{1^{\prime}}{}$ & 10.22 & 0.22 & $+\mathrm{I} \cdot 65$ & 10.25 \\
\hline 32 & $50^{\circ} 04^{\prime}$ & $5^{\circ} 45^{\frac{1}{2}}{ }^{\prime}$ & $5^{\circ} 42^{\prime}$ & $7^{\prime}$ & 10.24 & 0.24 & $+\mathrm{r} \cdot 68$ & 10.27 \\
\hline & & & $\theta_{\text {mean }}^{213^{\prime}}=\frac{\Sigma \theta}{\Sigma}$ & $\frac{\Delta \lambda}{\Delta \lambda}=\frac{37}{2}$ & $\frac{03}{3}=0.17^{\circ}$ & & 37.03 & \\
\hline
\end{tabular}

Assuming that all stations lay precisely on the fiftieth parallel the calculation gave as a first approximation a mean latitude temperature of $10.17^{\circ} \mathrm{C}$. However, some stations deviated $4^{\prime}$ from the parallel. A similar calculation for latitude $49^{\circ} 30^{\prime} \mathrm{N}$. had given the mean temperature for that latitude as 
I0. $48^{\circ} \mathrm{C}$. It was therefore possible to apply a correction of $0.0 \mathrm{I}^{\circ}$ per minute of latitude to correct each observed temperature along each latitude to $50^{\circ} 00^{\prime} \mathrm{N}$. or to $49^{\circ} 30^{\prime} \mathrm{N}$. precisely. This refinement increased the mean latitude temperature along $50^{\circ} \mathrm{N}$. by a mere $0.0 \mathrm{I}^{\circ} \mathrm{C}$. This figure was used for further development.

By similar means the mean temperature was computed for other lines of latitude where enough observations were available (Table 3 , column 4).

In order to use all the available observations and to distribute error and random deviations, it was assumed that the rate of decrease of temperature was linear with latitude. A least mean square of calculation then gave the relation

$$
T=10.46-\frac{0.712}{100}(\Phi-2970)
$$

where $\Phi$ is the station latitude and 2970 is the latitude $49^{\circ} 30^{\prime}$, each expressed in minutes of arc.

The final column in the Table shows the mean temperature for latitude computed in this way.

For a depth of Io m, at each of the 57 stations worked during the cruise of April 1950, the latitude temperature was then computed. Finally, the difference of each observed temperature from the computed latitude temperature was evaluated and plotted on a graph as in Fig. 4. The information will be used in a paper in preparation.

TABLE 3

$\begin{array}{ccccc}\text { Lat. } & \begin{array}{c}\text { Limits of long. } \\ \text { (W.) }\end{array} & \begin{array}{c}\text { No. of } \\ \text { observations }\end{array} & \begin{array}{c}\text { Observed on } \\ \text { lat. only }\end{array} & \begin{array}{c}\text { Mean square calc. } \\ \text { from whole area }\end{array} \\ \text { ('N.) } & 5^{\circ} \circ 5^{\prime}-9^{\circ} 00^{\prime} & 5 & 9 \cdot 65 & 9 \cdot 68 \\ 51^{\circ} 20^{\prime} & 4^{\circ} 45^{\prime}-9^{\circ} 15^{\prime} & 5 & 9.87 & 9 \cdot 82 \\ 51^{\circ} & 5^{\circ} 20^{\prime}-9^{\circ} 05^{\prime} & 6 & 9.98 & 10 \cdot 00 \\ 50^{\circ} 35^{\prime} & 5^{\circ} 42^{\prime}-9^{\circ} 15^{\prime} & 13 & 10.18 & 10 \cdot 25 \\ 50^{\circ} \circ 0^{\prime} & 4^{\circ} 45^{\prime}-9^{\circ} 15^{\prime} & 9 & 10.49 & 10 \cdot 46\end{array}$

It will be seen that, strictly speaking, the development has added nothing which could not have been deduced by careful drawing and study of a conventional chart of isothermal contours. However, to use a simile from electronics, the required information has been raised above the level of the background noise. The enclave of water north of Cornwall shows this well.

The technique has another application. One often needs to decide whether the sea at any time is warmer or colder than at some other time. Inevitably oceanographic observations are untidy and heterogeneous. Elimination of the 'Latitude Effect' should enable a lot of scattered observations to be summarized in a compact and convenient equation in standard form and to be used for practical ends. One such is fog forecasting where the forecaster 

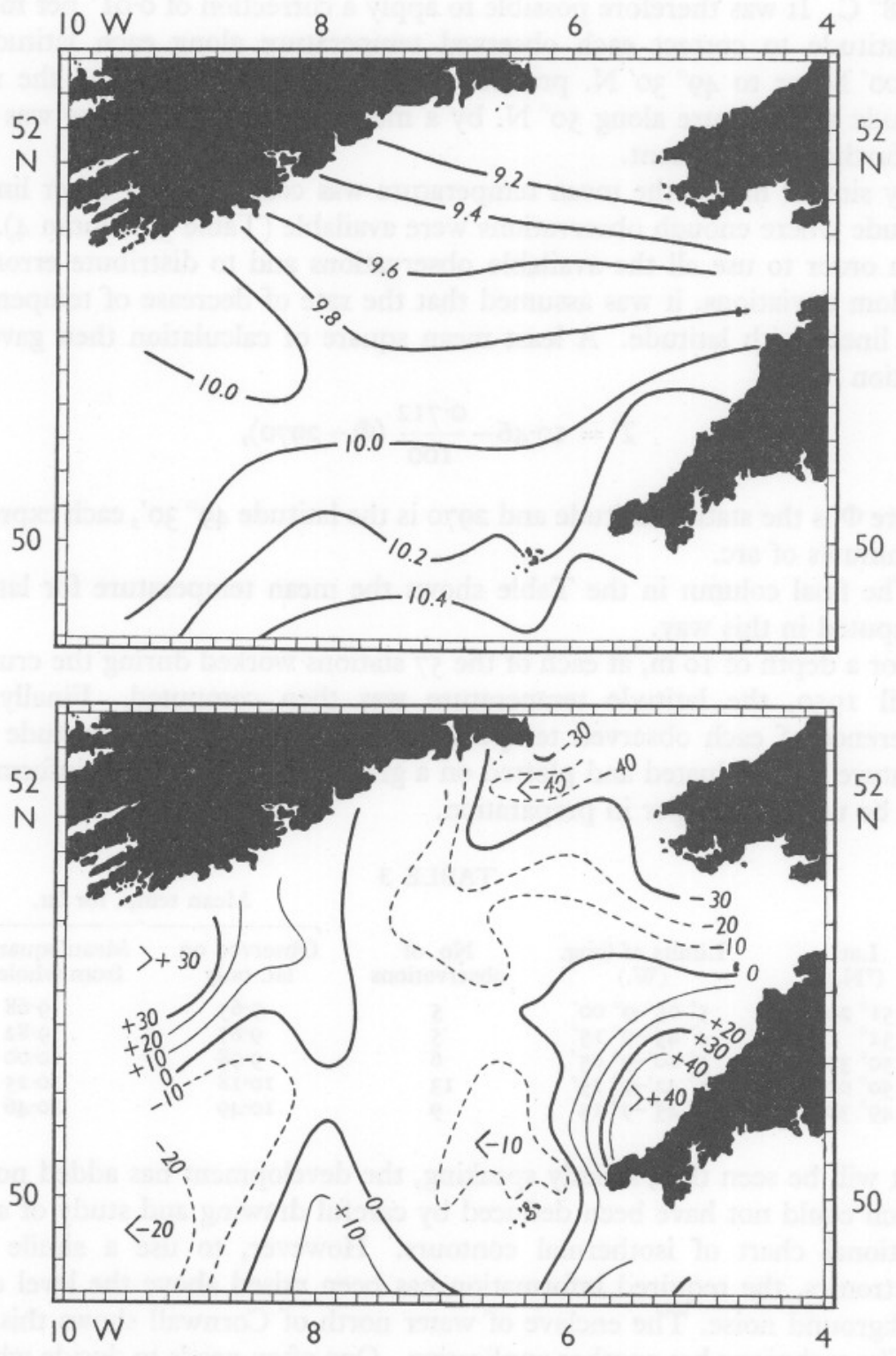

Fig. 4. Two ways of presenting sea temperatures in the Celtic Sea, I9-30 April r950 at Io m depth. Upper panel as conventional isotherms, lower panel as deviations from the latitude mean. 
needs much more information that he is every likely to get for all of the time and all of the area for which he needs it.

In an investigation where observations have been made in a symmetrical pattern, the calculation may be much curtailed. One could proceed straight into a least-mean-square calculation using all the data. But if some of the stations are clustered, as in April 1950 around the Scilly Isles, bias would be introduced by this short-cut.

\section{THE USE OF GEOPOTENTIAL TOPOGRAPHIES IN SHALLOW-WATER OCEANOGRAPHY}

In common practice geopotential topographies are drawn only in oceanic areas where there is a probability of a level surface at a depth in which no motion may reasonably be assumed. The lead set by Harvey (1929) for shallow water work has been rarely followed.

In shallow seas there can be no level surface of no motion. Nevertheless, in our own shallow-water work in the Celtic Sea we have always drawn geopotential topographies and have found them to have diagnostic value. Any deductions which may be drawn must always be consistent with the continuity of conservative and semi-conservative properties of the water.
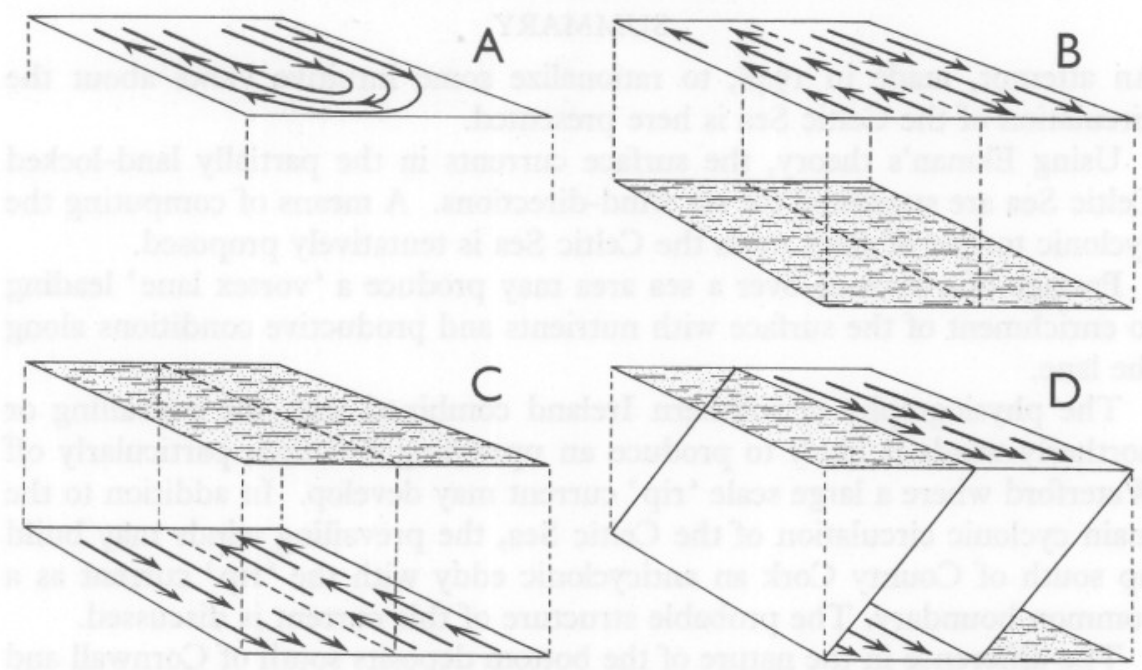

Fig. 5. Interpretations of a tongue in a geopotential topography.

Tongues on geopotential topographies (Fig. 5A) are usually interpreted as geostrophic surface flow along the isolines (Fig. 5B); similarly to geostrophic winds on a meterological isobaric chart. Occasionally, they may be interpreted as a precisely opposite bottom flow, the surface being considered a layer of no motion (Fig. 5C). There is, however, another possibility (Fig. 5D) 
which may often be important in shallow-water oceanography when water piled up against a coast by wind has to escape as a bottom or mid-water current flowing against the wind at the surface. In this the two halves of the geopotential topography may be interpreted oppositely, so that a picture emerges of a unidirectional current sloping from the surface where the conventional arrows face towards the tip of the tongue to the bottom where they face away from it. The maximum strength may well be in mid-water beneath the axis of the tongue.

Lateral mixing is usually considered as occurring across a more or less vertical boundary. Allowing for the vertical exaggeration of scale, the present interpretation of geopotential topography may require that the boundary between a current and its envelope of stationary water shall dip beneath the surface at an angle of only $\mathrm{I}^{\circ}$ or so with the horizontal.

Studies of eddy diffusion and eddy viscosity in such a situation take a different form when horizontal and vertical coefficients require to be replaced by oblique coefficients.

This theorem may be illustrated by the events in the Celtic Sea in April I950, described in a paper in preparation.

\section{SUMMARY}

An attempt, made in 1948 , to rationalize some intuitive views about the circulation of the Celtic Sea is here presented.

Using Ekman's theory, the surface currents in the partially land-locked Celtic Sea are suggested for six wind-directions. A means of computing the cyclonic torque of gales upon the Celtic Sea is tentatively proposed.

Passage of a cyclone over a sea area may produce a 'vortex lane' leading to enrichment of the surface with nutrients and productive conditions along the lane.

The physiography of southern Ireland combined with the prevailing or northerly winds is likely to produce an upwelling situation, particularly off Waterford where a large scale 'rip' current may develop. In addition to the main cyclonic circulation of the Celtic Sea, the prevailing winds may build up south of County Cork an anticyclonic eddy with the 'rip' current as a common boundary. The probable structure of this current is discussed.

The difference in the nature of the bottom deposits south of Cornwall and south of Ireland, regions with much in common, is considered in relation to the current régime and to biological productivity.

It is suggested that the Labadie Bank may affect the direction of currents, especially the intermittent County Cork anticyclonic eddy.

In both winter and summer it is suggested that events within the Scilly Island group may affect the currents in the neighbourhood, as at the Seven Stones Light Vessel. 
A method is given of eliminating the latitude effect from a study of temperature in a limited sea area.

A profitable method of applying information from geopotential topographies in shallow seas is described.

\section{REFERENCES}

Carruthers, J. N., Lawford, A. L. \& Veley, V. F. C., I95I. Studies of water movements and winds at various light vessels. II. At the Seven Stones Light Vessel near the Scilly Isles. F. mar. biol. Ass. U.K., Vol. 29, pp. 587-608.

COopes, L. H. N., I95I. Chemical properties of the sea water in the neighbourhood of the Labadie Bank. F. mar. biol. Ass., U.K. Vol. 30, pp. 2 I-6.

— I960. The water flow into the English Channel from the south-west. F. mar. biol. Ass. U.K., Vol. 39, pp. 173-208.

COOPER, L. H. N. \& VAUX, D., I949. Cascading over the continental slope of water from the Celtic Sea. F. mar. biol. Ass. U.K., Vol. 28, pp. 719-50.

Cromwell, T., 1956. "Eastropic expedition". Pacif. Fisherm., Vol. 54, No. 8, pp. 2529 [cit. W. Brandhorst, 1958, F. Cons. int. Explor. Mer, Vol. 24, pp. 16-29].

EкMAN, V. W., 1905. On the influence of the earth's rotation on ocean currents. Ark. Mat. Astr. Fys., Bd. 2, No. II, 52 pp.

Harvey, H. W., 1929. Hydrodynamics of the waters south east of Ireland. F. Cons. int. Explor. Mer, Vol. 4, pp. 80-92.

Matrhews, D. J., I9I4. The salinity and temperature of the Irish Channel and the waters south of Ireland. Sci. Invest. Fish. Br. Ire., Vol. 4, pp. I-26.

Robinson, A. H. W., I952. The floor of the British seas. Scot. geogr. Mag., Vol. 68, pp. 64-79.

SANDSTRÖM, J. W., I9I8. The hydrodynamics of Canadian Atlantic waters. Canad. Fish. Exped., 1914-15, pp. 221-343.

SHEPARD, F. P., I948. Submarine Geology. 348 pp. New York: Harper.

WILSON, D. P., I95I. A biological difference between natural sea waters. F. mar. biol. Ass. U.K., Vol. 30, pp. I-20. 